\section{EMBRYRIDDLE \\ Aeronautical University}

SCHOLARLY COMMONS
International Journal of Aviation, Aeronautics, and Aerospace

\title{
Aviation Bird Hazard in NEXRAD Dual Polarization Weather Radar Confirmed by Visual Observations
}

\author{
Bradley M. Muller \\ Embry-Riddle Aeronautical University - Daytona Beach, mullerb@erau.edu \\ Frederick R. Mosher \\ Embry-Riddle Aeronautical University - Daytona Beach, moshe774@erau.edu \\ Christopher G. Herbster \\ Embry-Riddle Aeronautical University - Daytona Beach, herbstec@erau.edu \\ Anthony T. Brickhouse \\ Embry-Riddle Aeronautical University - Daytona Beach, brickhoa@erau.edu
}

Follow this and additional works at: https://commons.erau.edu/ijaaa

Part of the Aviation Safety and Security Commons, and the Meteorology Commons

\section{Scholarly Commons Citation \\ Muller, B. M., Mosher, F. R., Herbster, C. G., \& Brickhouse, A. T. (2015). Aviation Bird Hazard in NEXRAD Dual Polarization Weather Radar Confirmed by Visual Observations. International Journal of Aviation, Aeronautics, and Aerospace, 2(3). https://doi.org/10.15394/ijaaa.2015.1045}

This Article is brought to you for free and open access by the Journals at Scholarly Commons. It has been accepted for inclusion in International Journal of Aviation, Aeronautics, and Aerospace by an authorized administrator of Scholarly Commons. For more information, please contact commons@erau.edu. 


\section{Aviation Bird Hazard in NEXRAD Dual Polarization Weather Radar Confirmed by Visual Observations}

\section{Cover Page Footnote}

Acknowledgements. This research benefited from the government-sponsored NSF Unidata program and software, specifically the IDV software package provided by Unidata (www.unidata.ucar.edu/software/). We thank three anonymous reviewers who made suggestions that strongly improved the manuscript, and David Ison and Chip Wolfe of IJAAA who assisted with the inclusion of the animation in the metadata for this article. 
Since the inception of human flight over 100 years ago, birds have shared the airspace with aircraft, creating the potential for catastrophic consequences. This was highlighted by the "Miracle-on-the-Hudson" accident of U.S. Airways Flight 1549 in 2009. The Airbus A320 had just taken off from New York City's La Guardia Airport when it collided with a flock of Canada Geese. Both engines ingested birds, then lost power forcing the aircraft to ditch in the Hudson River. In that case, the pilots were able to successfully crash-land the plane on the water with no loss of life and only a few serious injuries to passengers.

The Federal Aviation Administration (FAA) (2014) reports that globally, wildlife strikes on aircraft during the years 1990-2013 killed more than 255 people and destroyed 243 airplanes. Furthermore, each year thousands of bird strikes on aircraft occur in the U.S. (FAA, 2014). Burger (1983) has suggested that one reason for increasing numbers of bird/aircraft encounters is that a newer generation of turbine engines is so efficient and quiet that birds are less able to detect and avoid them, while Dolbeer and Wright (2009) have associated an increased number of bird strikes with both increasing bird populations and a rise in air traffic. A recent FAA advisory circular (FAA, 2010) has suggested that airports with a bird problem consider adoption of "avian radar" to help detect birds in the airspace near airports. NASA has implemented this tool for use with rocket launches at Kennedy Space Center.

While perhaps not a comprehensive solution to the problem, this paper highlights Next Generation Radar (NEXRAD), the National Weather Service (NWS) radar system, as a potential tool for at least providing additional situational awareness to flight operations for those educated in recognizing bird signatures. Weather radar is designed to detect "targets" that consist of ensembles of precipitation particles such as raindrops, snowflakes, and hailstones. This is achieved through the transmission of short pulses of microwave electromagnetic radiation in a narrow beam scanning the horizon, which backscatters from the precipitation so that "reflectivity," also sometimes described as "echo intensity," and other aspects of the returning signal can be detected and measured by the radar. "Reflectivity" is a measure of the strength of the returning signal (adjusted for distance to the targets) and is positively correlated with both the size and the number-concentration of the targets and hence, the rain rate. It is typically presented in units of dBZ - decibels of reflectivity. However, non-precipitation objects in the environment can also reflect microwave radiation and have been documented in 
weather radar, including birds, insects, and bats (Martin and Shapiro, 2007), ashes in smoke plumes (Jones, et al. 2009), tornado debris (Magsig \& Snow 1998; Burgess, et al. 2002, Ryzhkov, et al. 2005), chaff (Maddox, et al. 1997), and ground-based objects such as trees, buildings and even wind turbines (Isom, et al 2009). Collectively, these are known as "clear-air echoes." Section 2 of this study provides a summary of the theory for determining bird numbers from reflectivity, while Section 3 presents estimates pertaining to the specific bird echoes documented herein.

Bird signatures were first documented in aircraft surveillance radar by Lack and Varley (1945-see, e.g., Chilson, et al. 2012; Eastwood, et al. 1962; Gauthreaux \& Belser 1998). In weather radar, the forms of interference from birds have evolved over time as the technology of the radar networks has advanced. Before the 1990's the National Weather Service radar network provided only reflectivity values as an operational product, so that bird signatures would have appeared strictly as echo intensity patterns. When the NWS operational radar network was upgraded to NEXRAD WSR-88D's (1988, Doppler) in the early 1990's, three "level II" products became available: base reflectivity $\left(Z_{\mathrm{H}}\right.$, the reflectivity of a horizontally polarized signal $\left.{ }^{1}\right)$, base velocity $\left(\mathrm{V}_{\mathrm{r}}\right.$, the radial or Doppler velocity) and base spectrum width, a measure of velocity variability within a radar pulse volume (Crum \& Alberty, 1993). In NEXRAD, the presence of birds was found to cause bias in estimates of Doppler radar winds (Gauthreaux, et al. 1998; Zhang, et al. 2005) as well as affecting reflectivity.

Starting in 2011 and ending in 2013, the NWS completed the next major upgrade to its operational weather radar network to "dual polarization." The new WSR-88D "dual pol" configuration generates a suite of Level II products that contains the original three plus four new dual polarization products (Kumjian 2013) based on various comparisons between both vertically and horizontally polarized signals: the Correlation Coefficient (CC), differential reflectivity $\left(Z_{D R}=Z_{H}-Z_{v}\right.$, i.e., the difference between the horizontally and vertically polarized signals), and two others not used in this study. Kumjian (2013) presents a more complete description of the new NEXRAD "dual pol" variables. Both CC and ZDR can help

\footnotetext{
${ }^{1}$ Horizontal polarization means that from the perspective of the radar, the electrical part of the electromagnetic signal oscillates side to side, parallel to the horizon, as the waves propagate toward the horizon.
} 
reveal signatures of birds due to the birds' shapes deviating from sphericity, and the variety of sizes and shapes of the targets within the pulse volume.

Flying birds can produce different patterns of reflectivity in the radar, not all of which are easily recognizable, even among experts. There is controversy, in fact, about whether some clear-air echoes are birds or insects. When radar is used in the emerging scientific discipline of aeroecology (Chilson, et al. 2012), Martin and Shapiro (2007) point out that ornithologists are biased toward the interpretation that the targets are birds, while entomologists are likely to assume they are insects.

$\mathrm{V}_{\mathrm{r}}$ can be used to help distinguish whether clear-air echoes are insects or birds. Weather radar shows velocity only if there is a sufficient concentration of radar targets to reflect a signal back to the radar. By convention, target movement with a component away from the radar or "outbound" is given a positive value, while movement toward the radar or "inbound" is given a negative value. Outside the region close to the radar where there may be insects and other clear-air targets returning signal, Doppler velocities usually exist only where there is precipitation on the display. The precipitation particles (drops) blow with the ambient wind, and therefore the Doppler velocity of these targets is assumed to be that of the air. Birds, however, are big and strong enough to fly independently of the wind, hence the concern over bias from birds in the wind estimates, since the radar does not "know" what is causing the target movement, but it is assumed to be identical to that of the air. If the echo velocities differ significantly from the ambient wind determined by other means, meteorologists may recognize that specific clear-air echoes are more likely to be birds rather than insects (Martin \& Shapiro 2007).

One signature that can reliably be identified as birds is the "roost ring" (see Gauthreaux \& Belser's 1998 observation in Figure 7), when birds are taking off from their roosting positions. It appears as an expanding circle of high reflectivity that typically originates before sunrise and lasts for an hour or two. In the early days of radar up to 1970, clear-air echoes were often referred to as "angels" (Martin \& Shapiro 2007). So-called radar "ring-angels" were first documented in the literature by Elder (1957), but not initially recognized as birds. Eastwood, et al. (1962) associated such ring-shaped signatures with the roosting behavior of starlings. Ring-shaped signatures occurring around sunrise are likely to be birds, while those occurring around sunset may be more likely to be bats (Martin \& Shapiro 2007). 
Roost rings are common in Florida and frequently seen in early-morning NEXRAD observations during the spring, when birds are plentiful and beginning their migrations back to northern locales. This paper presents a roost ring signature on the NWS Melbourne (KMLB) radar that began just before sunrise on February 6, 2013, and flew toward our location in Daytona Beach. This afforded a unique opportunity to make direct visual observations of flocks of birds that most likely caused the radar signatures near and over Daytona Beach International Airport (KDAB). According to Martin and Shapiro (2007), ground truth observations of the source of clear-air echoes are rare. The purpose of this paper is threefold: 1) to present a case study as a means to educate the aviation community in recognizing roost ring bird signatures in familiar and long-established NEXRAD weather radar reflectivity and Doppler velocity products; 2) to show how some of the new "dualpol(arization)" products can help to discriminate the bird signatures from meteorological echoes; and 3) to document this unusual case of bird signatures confirmed by direct visual observations.

\section{Literature Review}

\section{Radar Theory of Birds as "Targets" in NEXRAD Reflectivity}

Radars determine reflectivity by measuring two things: the power or signal returned from targets, and the distance to those targets. The returned signal strength depends on radar-specific quantities such as power transmitted, wavelength, antenna gain, and volume of the beam, as well as the number and size of the objects scattering the radar signal, and their distance from the radar according to the inverse square law. The radar "normalizes" the signal strength information to account for its dependence on the radar-specific parameters and distance so that only target characteristics determine the quantity, $Z$, the "radar reflectivity factor." Thus, $Z$ is actually an inherent property of the targets, is independent of their distance to the radar, and is not radar-specific. For meteorological targets, $\mathrm{Z}$ can span a huge range of values from $0.001 \mathrm{~mm}^{6} \mathrm{~m}^{-3}$ for fog droplets to $30,000,000 \mathrm{~mm}^{6} \mathrm{~m}^{-3}$ for softballsized hail, so for display, $\mathrm{Z}$ is converted to the familiar logarithmic scale of "reflectivity" $\left(\mathrm{Z}_{\mathrm{H}}\right.$ in decibels of reflectivity $\mathrm{dBZ}$, for the horizontal polarization) via the relationship:

$$
Z_{H}=10 \cdot \log _{10} Z
$$


The scattering cross-sectional area of a target is a function of the size of the target, the wavelength of the radar, and the composition of the target material. Black and Donaldson (1999) have developed the WSR88-D radar relationship for the radar reflectivity factor, $\mathrm{Z}$, to the bird density, $\mathrm{N}$ (in units of number of birds per $\mathrm{km}^{3}$ ), as:

$$
Z=N \cdot \sigma / 28
$$

where $\sigma$ is the average radar cross section per bird and the constant 28 is a function of the WSR-88D characteristics. Black (2000) lists several different bird cross sectional areas, with the small old world chiffchaff warbler being $8 \mathrm{~cm}^{2}$, an European starling being $22 \mathrm{~cm}^{2}$, a Swainsonn's thrush being $22 \mathrm{~cm}^{2}$, and different North American wood warblers ranging between 7 and $15 \mathrm{~cm}^{2}$. As discussed in more detail in Section 3, we visually determined the birds in question for this study to be tree swallows. A tree swallow is slightly larger than a wood warbler, so an interpolated scattering cross sectional area of $12.3 \mathrm{~cm}^{2}$ is used here to estimate numbers of birds based on reflectivity. Calculating the density of birds, $\mathrm{N}$, from the reflectivity, $\mathrm{Z}_{\mathrm{H}}$, in $\mathrm{dBZ}$ is simply a matter of solving Equation (1) for $\mathrm{Z}$ :

$$
Z=(10)^{\frac{Z_{H}}{10}}
$$

then solving Equation (2) for N,

$$
N=28 \cdot Z / \sigma
$$

and plugging in appropriate values. Eqs. (3) and (4) will be used to estimate numbers of birds measured by the KMLB NEXRAD in Section 3.

\section{NEXRAD Dual Polarization Bird Signatures on February 6, 2013}

Figure 1 shows reflectivity $\left(\mathrm{Z}_{\mathrm{H}}\right.$ in $\mathrm{dBZ}$ ) on a map of the case study area at 11:50 UTC (6:50 EST) on February 6, 2013 when the bird signature first appeared. For geographical reference, Interstate 95 is the red line running north-south parallel to the coastline, while Interstate 4 comes in at an angle from the southwest, intersecting I-95 in Daytona Beach. KDAB and Embry-Riddle Aeronautical University (ERAU) are just to the northeast of that intersection. The birds are initially seen on the map adjacent to Rockledge, near Lake Poinsett (just west of 
Rockledge), as a spot of high $\mathrm{Z}_{\mathrm{H}}$ of about $50 \mathrm{dBZ}$ (identified by a red arrow), comparable to the reflectivity in a typical thunderstorm. Using Equations (3) and (4) based on Black and Donaldson (1999), and making the assumption that the birds are all flying at roughly the same altitude above the ground to convert the volume density to birds per area, this maximum $\mathrm{Z}_{\mathrm{H}}$ translates to a "density" of approximately 2300 birds over an area $100 \mathrm{~m}$ by $100 \mathrm{~m}$, roughly the size of two (American) football fields. Making similar calculations for each pixel in the apparent bird area according to the value of $\mathrm{Z}_{\mathrm{H}}$ in each pixel, then summing up over the total area of the bird pixels, we obtain an estimate of 1.7 million birds in the initial flight shown in Fig. 1. The WSR-88D radar beam has a beam width of approximately 1 degree, with the beam pointed 0.5 degrees above the horizon for the lowest "tilt" displayed here. This results in the sampling of only part of the atmosphere. There could be birds above and/or below the beam which are not detected by the radar on this tilt. Hence these number-of-birds calculations should be considered as approximate numbers rather an absolute number of birds present. It also should be noted that birds have a very large diameter in comparison with a raindrop, so it takes many fewer birds within the sampling volume of the radar beam to produce the same reflectivity in comparison with raindrops. Light rain showers that most likely were not hitting the ground also are evident in the figure.

Figures 2-8 present a sequence of selected images created using Unidata's Integrated Data Viewer (IDV) and showing the roost ring expanding from Lake Poinsett, then moving north toward Daytona Beach. In those images, coastlines and county outlines are in red, and I-95 and I-4 are in yellow. Figures 2-6 are zoomed in on the expanding roost ring south of Daytona Beach so that Daytona is not within their field-of-view. Each figure contains four panels: 1) Upper left: reflectivity $\left(Z_{H}\right.$ in dBZ) overlaid on GOES visible imagery 2) Upper right: Doppler velocity $\left(\mathrm{V}_{\mathrm{r}}\right.$ in kts) on GOES IR $(10.7 \mu \mathrm{m})$ imagery 3$)$ Lower left: correlation coefficient (CC) on GOES IR imagery 4) Lower right: Differential reflectivity ( $Z_{D R}$ in dBZ) on GOES IR imagery. An animation using the same format, and containing every radar frame during the entire sequence, has been 


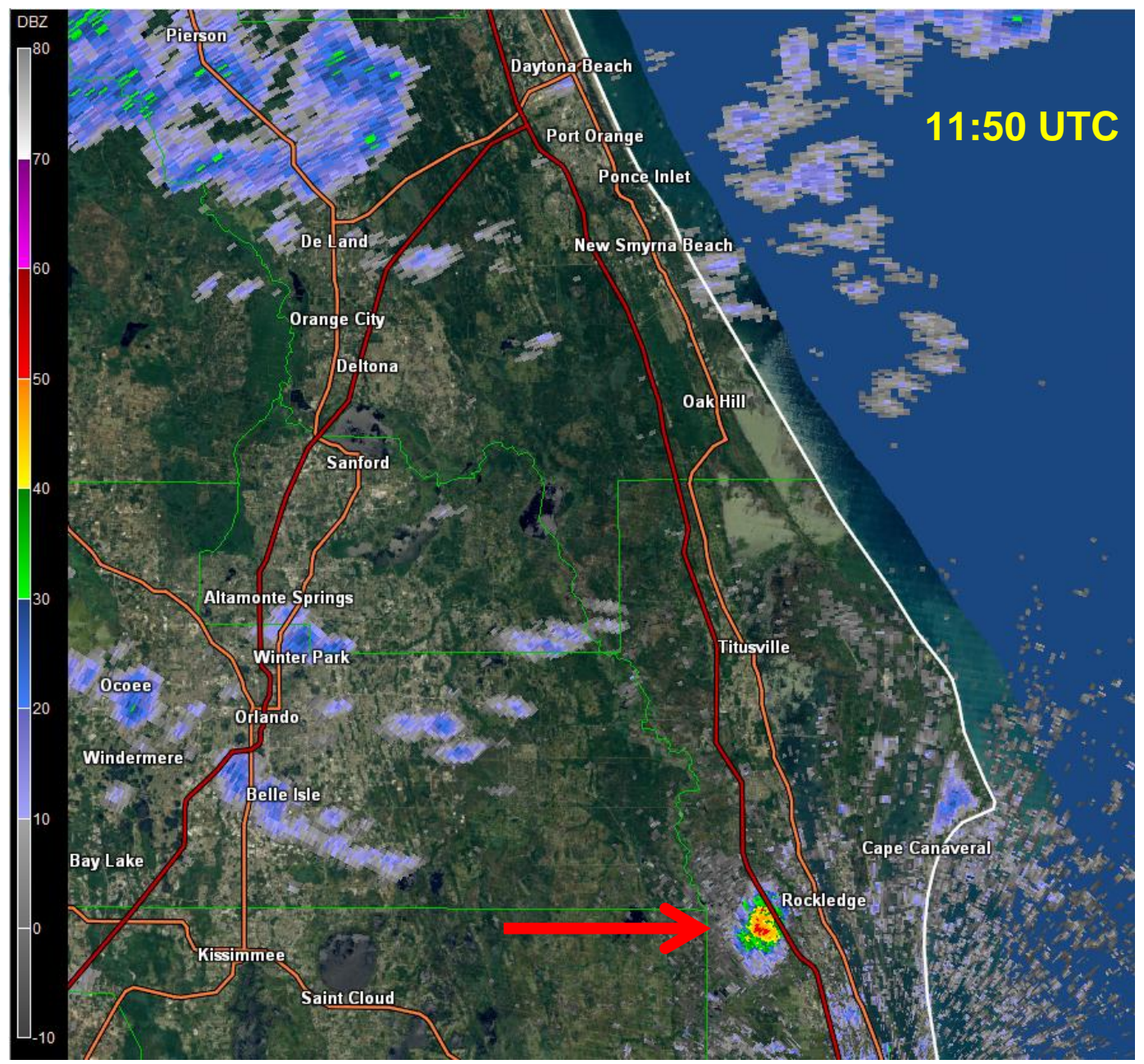

Figure 1. NEXRAD reflectivity $\left(\mathrm{Z}_{\mathrm{H}}\right.$ in $\left.\mathrm{dBZ}\right)$ at 11:50 UTC (6:50 EST) on February 6, 2013 when the bird signature first appeared, superimposed on a map of the case study area. I-95 is the red line running north-south parallel to the coastline, while I-4 comes in at an angle from the southwest, intersecting I-95 in Daytona Beach. KDAB and Embry-Riddle Aeronautical University (ERAU) are just to the northeast of that intersection. State highways are orange. A red arrow points to the initial bird signature showing $50 \mathrm{dBZ}$, comparable to that of a typical thunderstorm. Light rain showers that probably were not hitting the ground also can be seen. 


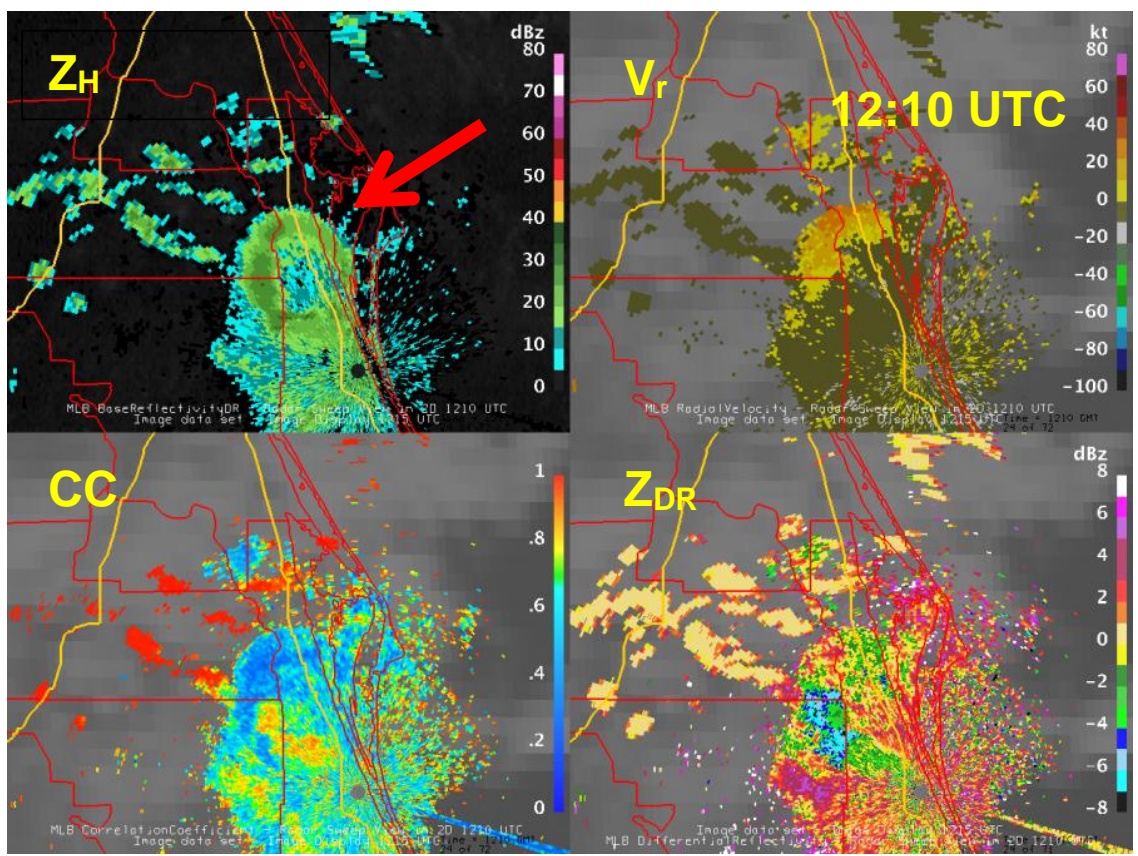

Figure 2. Four panels showing 0.5 degree elevation angle (this is the lowest angle possible) NEXRAD dual polarization radar products for 12:10 UTC (7:10 EST). overlaid on nearly simultaneous GOES satellite imagery. Upper left: Reflectivity $\left(\mathrm{Z}_{\mathrm{H}}\right.$ in $\left.\mathrm{dBZ}\right)$ overlaid on GOES visible imagery (note that the satellite image is dark because it is prior to sunrise). Upper right: Doppler velocity ( $\mathrm{V}_{\mathrm{r}}$ in $\mathrm{kts}$ ) on GOES IR $(10.1 \mu \mathrm{m})$ imagery. Lower left: Correlation coefficient (CC) on GOES IR imagery. Lower right: Differential reflectivity ( $Z_{D R}$ in $\mathrm{dBZ}$ ) on GOES IR imagery. The red arrow points to the bird signatures in $\mathrm{Z}_{\mathrm{H}}$. There is a sunrise spike in $\mathrm{CC}$ and $\mathrm{Z}_{\mathrm{DR}}$ but the sunrise spike in $\mathrm{Z}_{\mathrm{H}}$ is out of the figure to the southeast. The position of the radar is evident as a "hole" south of the roost ring.

included with this article just below the abstract, so that the reader can view the radar bird patterns in motion. The individual images were created with the IDV under the LINUX computer operating system, labeled using Imagemagick, and converted to an animated gif file using the LINUX "convert" command.

At 1210 UTC (7:10 EST), the bird signature has expanded into the typical roost ring pattern as the birds spread away from their initial location at Lake Poinsett (Fig. 2). The maximum reflectivity is now considerably lower than in Fig. 1, with a value between 30 and $35 \mathrm{dBZ}$. Converting $35 \mathrm{dBZ}$ back to $\mathrm{Z}$ based on Eq. 
(3), yields $Z=3162$, then using Eq. 4 based on the Black and Donaldson (1999) relationship for the bird density $\mathrm{N}$ gives approximately $7200 \mathrm{birds} / \mathrm{km}^{3}$. Again assuming the birds are all flying at approximately the same level, the volume density can be converted into the number of birds per area. This converts to 72 birds over an area $100 \mathrm{~m}$ by $100 \mathrm{~m}$, again, roughly the size of two (American) football fields. Counting the birds in Fig. 9 shows 43 birds in the field of view of the camera, in the same "ballpark" as the calculations. Measuring the dimension of the bird ring in Fig. 2 yields an area of approximately $415 \mathrm{~km}^{2}$, which translates to approximately 3 million birds shown on the radar.

The radar location is evident as a round "hole" in the reflectivity values to the south of the roost ring (Fig. 2). Note that there is a "sunrise spike" in CC and $Z_{\mathrm{DR}}$ southeast of the radar location. It also exists in $\mathrm{Z}_{\mathrm{H}}$, but is not evident in this figure because it is out of the field-of-view in this zoomed figure. This is indicative of the sun shining directly into the radar dish as it comes up over the horizon. ${ }^{2}$ The northern end of the roost ring shows the maximum $\mathrm{V}_{\mathrm{r}}$ of again $26 \mathrm{kts}$ outbound moving northward. The CC product at 12:10 UTC (7:10 EST) shows a minimum value of around 0.2 (blue) associated with the birds. Values of this magnitude are typically associated with non-meteorological echoes; precipitation, on the other hand, typically shows values of 0.9 to 1.0 (Crum et al. 2013). The pockets of uniformly red values close to 1.0 are most likely rain showers at the vertical level of the radar beam (which can be thousands of feet above ground level at the farther distances). Thus, the $\mathrm{CC}$ product helps considerably in distinguishing bird from precipitation echoes. $Z_{\mathrm{DR}}$ shows a coincident spot of negative values as low as -6 $\mathrm{dBZ}$. While non-meteorological echoes can be positive or negative, precipitation is not typically negative to this magnitude, so the indication is that these are nonmeteorological targets. $Z_{\mathrm{DR}}$ varies between positive and negative values depending on the alignment of the migrating birds - head-to-tail orientation parallel to the beam gives positive values, while perpendicular yields negative values (Crum, et al. 2013).

Figures 3-7 are included as an overview of the evolution of the roost ring as its northern portion moves northward toward Daytona Beach at up to $26 \mathrm{kts}$, while

\footnotetext{
${ }^{2}$ While solar radiation is predominantly in the visible part of the spectrum, it also contains some electromagnetic radiation at the microwave frequency of the NEXRAD, which is processed by the radar receiver just as the NEXRAD signal itself is, and therefore shows up in the form of the spikes seen in Fig. 2.
} 
the animation under the abstract shows the signatures in motion. Figures 7 and 8 shift the field-of-view northward following the northern segment of the roost ring as it approaches and moves into Daytona. Daytona's location is near the intersection between I-95 and I-4. By 1320 UTC (9:20 EST, Fig. 7) the signature has lost its identity as a ring, but the very-low blue values of $\mathrm{CC}$ indicate that the remaining arc-shaped region approaching the Daytona Beach area still is composed of nonmeteorological targets, in this case, birds.

Figure 8 shows a lobe of reflectivity that has moved ahead of the main bird reflectivity arc and directly over the Daytona Beach International Airport/EmbryRiddle Aeronautical University area. It was around this time that two of the authors of this study went to the roof of the College of Aviation (COA)

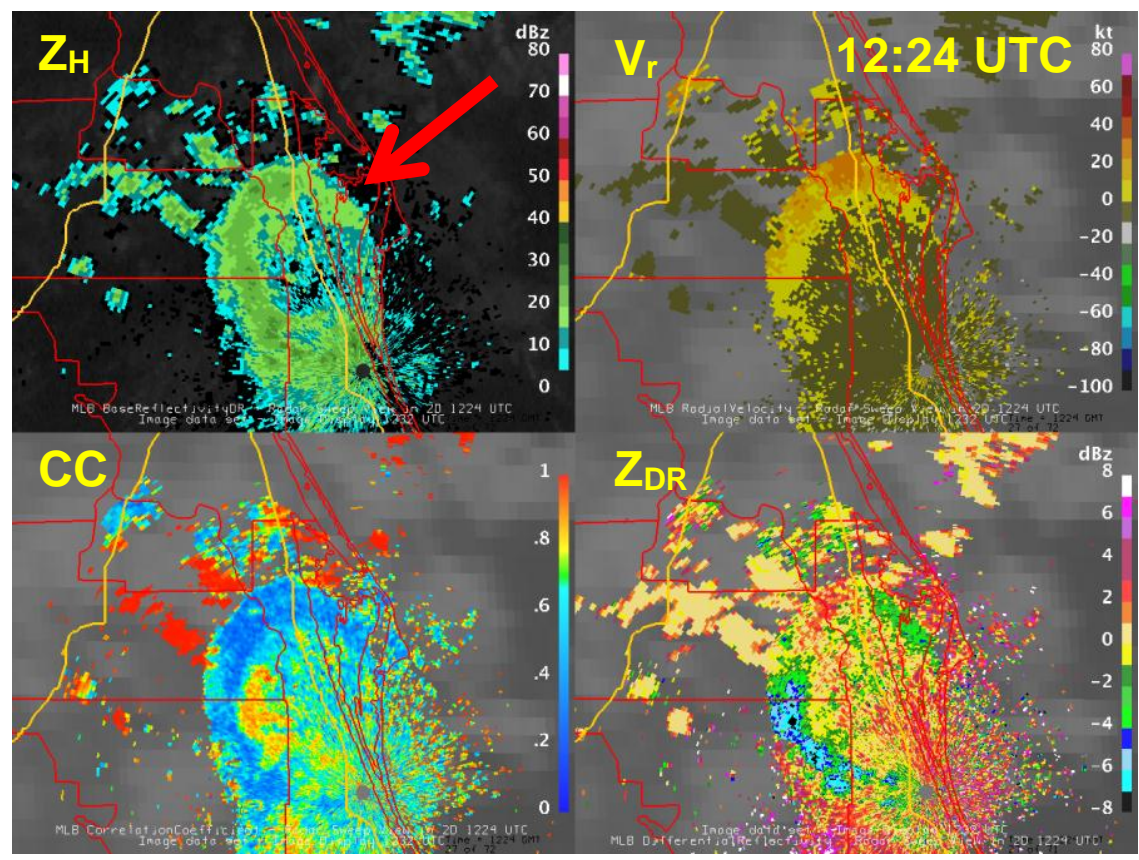

Figure 3. Same as Fig. 2, but for 12:24 UTC (7:24 EST).

building of ERAU with binoculars in an attempt to spot birds that they presumed had flown northward in the NEXRAD roost ring reflectivity signature. The COA building overlooks the KDAB runways a few hundred yards away. The two observers were able to discern sporadic small flocks of birds in the vicinity of the airport and around the COA building, but even with binoculars it was impossible to identify the type of birds in the flocks. We estimate there were hundreds to 
thousands of birds visible to us. It should be noted that the radar beam becomes progressively higher above the ground as distance from the radar increases and that KDAB is approximately 80 miles from the radar located at KMLB. Therefore, birds seen visually at KDAB may not be exactly the same birds as the radar signature over KDAB (Fig. 8), since in a standard atmosphere the height of the 0.5 degree elevation angle beam is about 8,000 feet over Daytona. On the other hand, left over nighttime temperature inversions in the lower part of the troposphere are likely to super-refract the beam by an unknown amount, so that its actual height is closer to the surface, but it is still most likely well above the elevation of the birds identified visually from our vantage point on the roof of the three-story COA building.

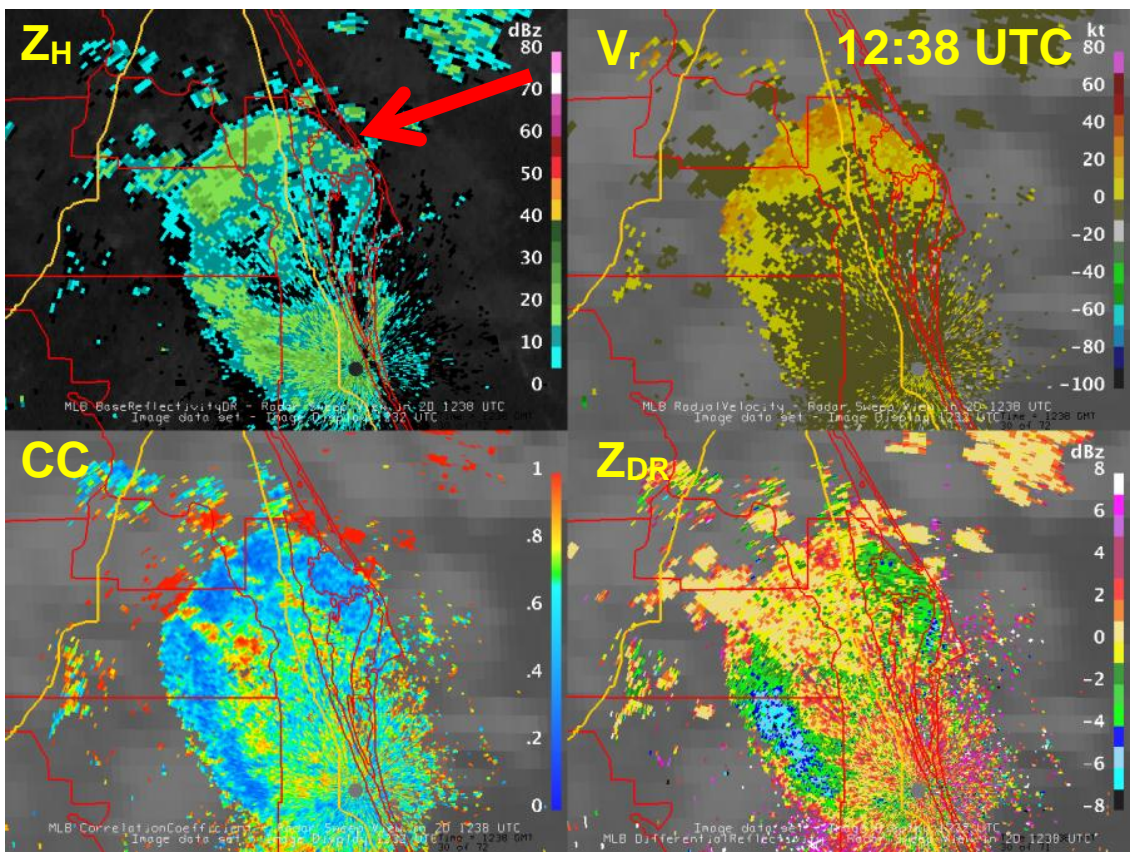

Figure 4. Same as Fig. 2, but for 12:38 UTC (7:38 EST). 
International Journal of Aviation, Aeronautics, and Aerospace, Vol. 2 [2015], Iss. 3, Art. 6

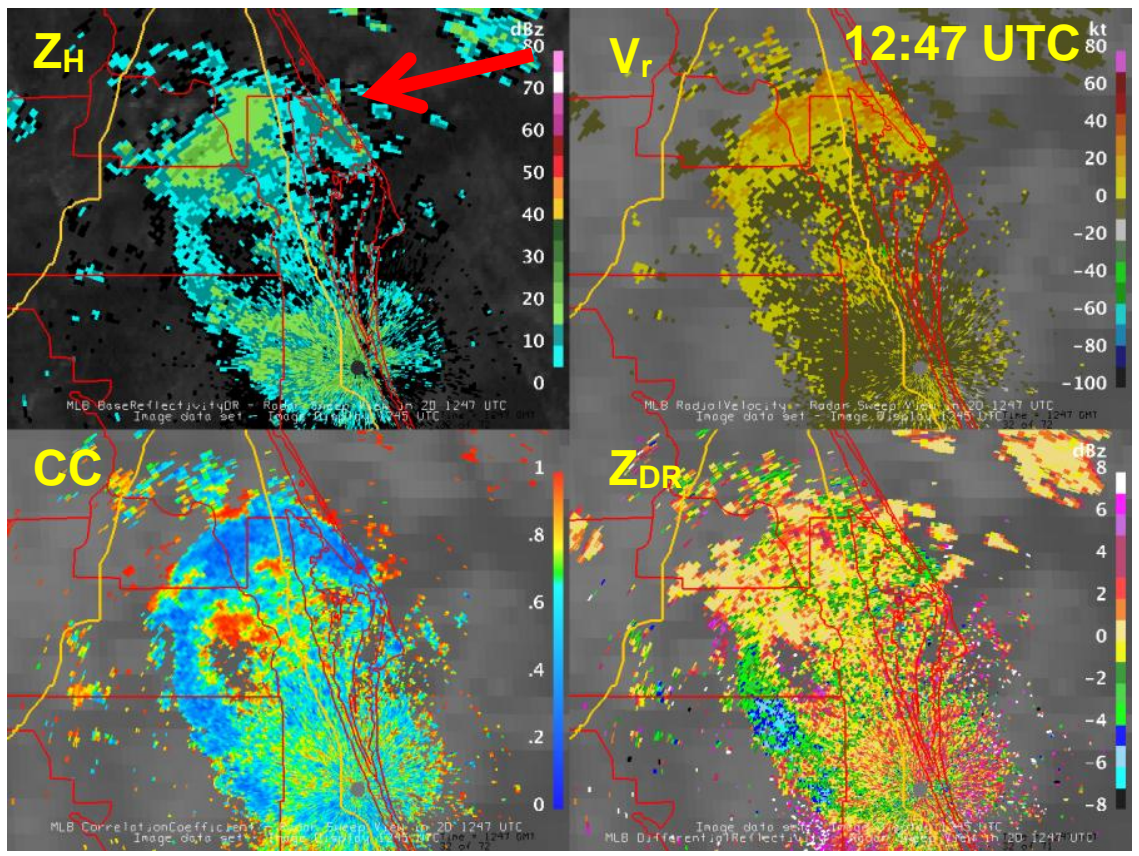

Figure 5. Same as Fig. 2, but for 12:47 UTC (7:47 EST).

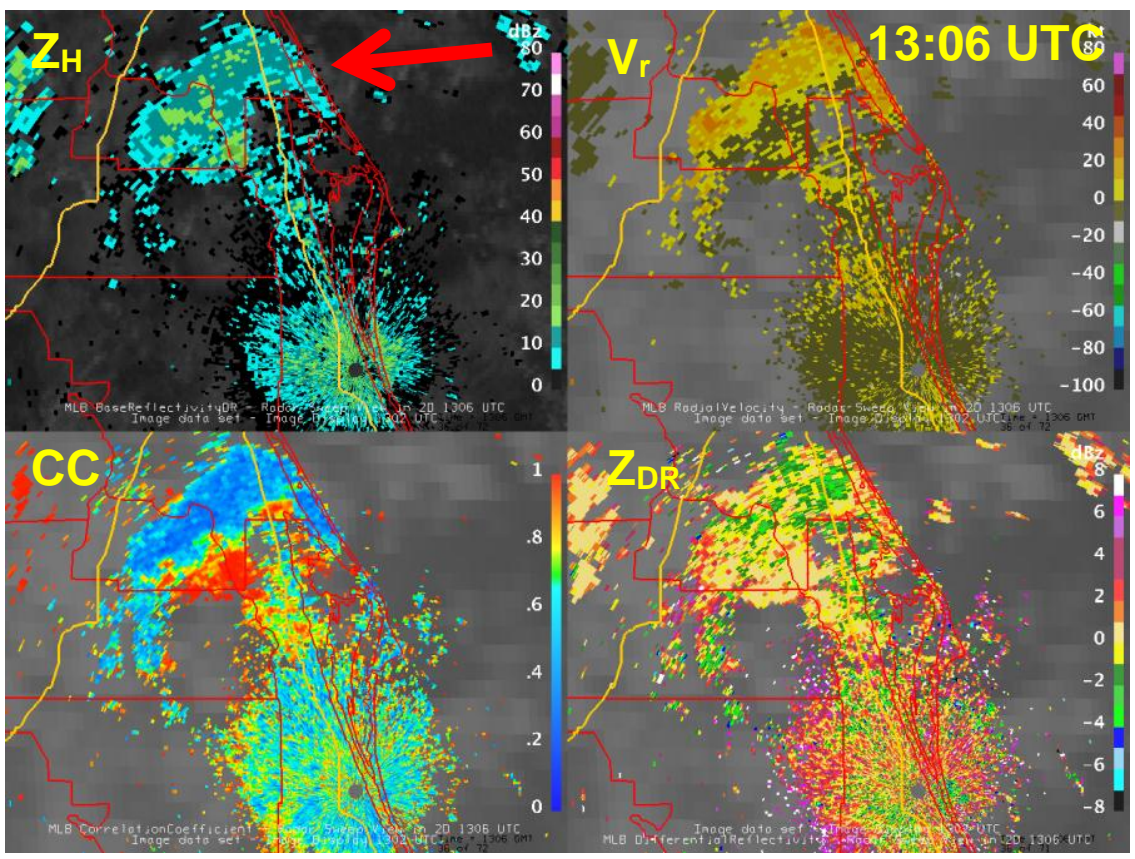

Figure 6. Same as Fig. 2, but for 13:06 UTC (8:06 EST). 


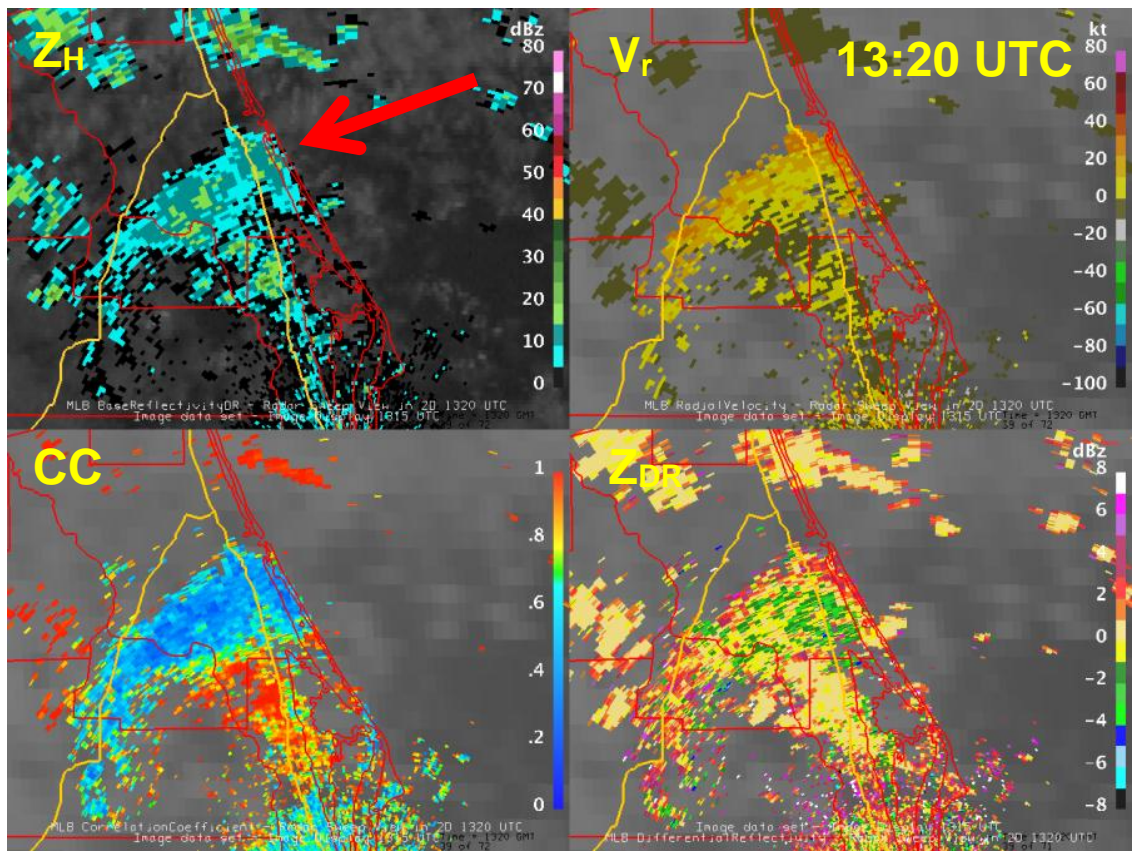

Figure 7. Same as Fig. 2, but for 13:20 UTC (8:20 EST).

Radar roost ring signatures similar to those on Wednesday, February 6, 2013 occurred around sunrise on February 7 and 8 emanating from the same location, although none showed the clear progression toward Daytona Beach that was seen on the $6^{\text {th }}$. On Friday, February 8, one of the authors (Mosher) was able to travel to the source of the clear-air echoes during the afternoon and photograph birds coming in to roost near Lake Poinsett (Fig. 9). The author, a member of the Audubon Society, visually identified the source of the clear-air echoes as thousands of tree swallows (Tachycineta bicolor). Tree swallows are known to winter in Florida and often take off in large flocks before sunrise.

\section{Conclusions}

This research has demonstrated dual polarization weather radar signatures of birds from February 6, 2013, from the KMLB NEXRAD weather radar in two conventional Doppler radar products, $\mathrm{Z}_{\mathrm{H}}$, and $\mathrm{V}_{\mathrm{r}}$, and two "dual pol" products, $\mathrm{CC}$, and $Z_{D R}$. The bird signatures occurred in a relatively recognizable pattern called a roost ring, that originated from Lake Poinsett, Florida, and whose northern end moved toward Daytona Beach at a maximum speed of $26 \mathrm{kts}$, according to Doppler velocity estimates. The roost ring pattern showed up in the $\mathrm{CC}$ and $\mathrm{Z}_{\mathrm{DR}}$ products as 
well as $\mathrm{Z}_{\mathrm{H}}$ and $\mathrm{V}_{\mathrm{r}}$. $\mathrm{CC}$ is especially useful at helping to discriminate bird signatures from precipitation as values for birds are very low (less than 0.6 and often around 0.2-0.3, appearing blue in the standard color

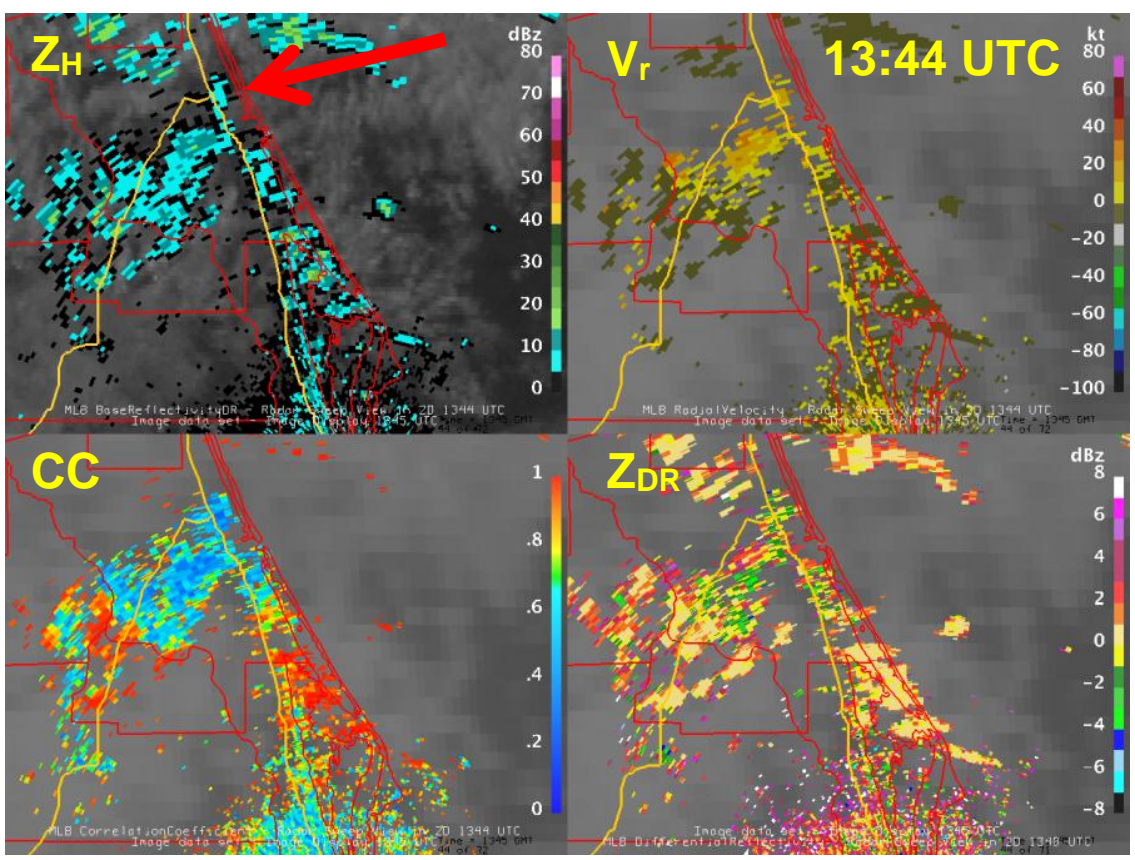

Figure 8. Same as Fig. 1, but for 13:44 UTC (8:34 EST). A lobe of reflectivity has moved northward ahead of the main group of birds and is roughly over the Daytona Beach International Airport.

scheme) whereas precipitation is usually between 0.9 and 1.0. ZDR values of birds in this study are often strongly positive or negative ranging from approximately 4 to $-8 \mathrm{dBZ}$, while values of the light precipitation seen here are generally slightly positive and close to zero. Visual observation from the roof of the College of Aviation Building at ERAU confirmed that the signatures were caused by birds, and subsequent investigation was able to identify the species as tree swallows. 


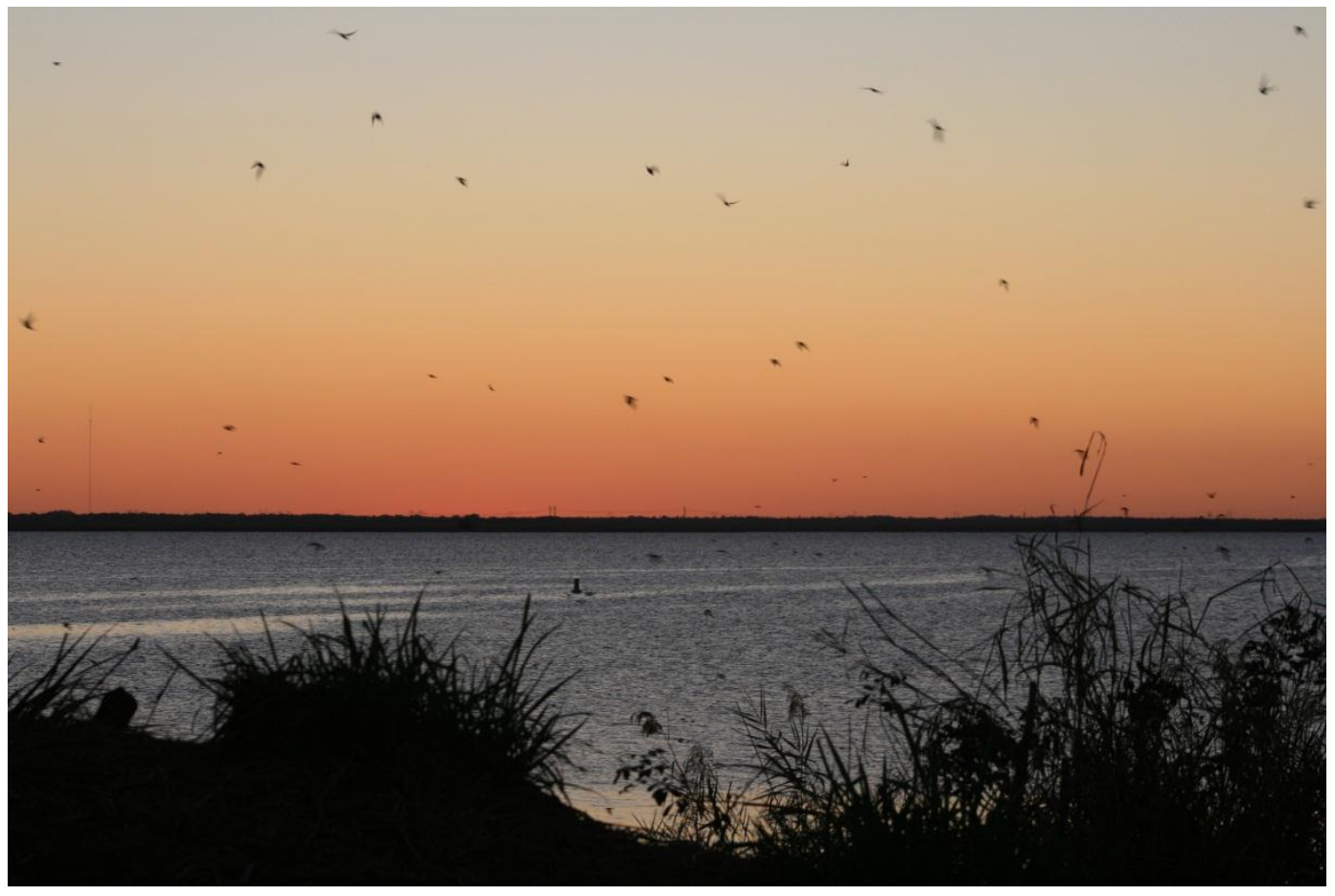

Figure 9. Tree swallows coming in to roost just after sunset at Lake Poinsett, Florida. Photo by Fred Mosher. 


\section{References}

Black, J. E., \& Donaldson, N. R. (1999). Comments on "Display of bird movements on the WSR-88D: patterns and quantification". Weather and Forecasting, 14(6), 1039-1040. doi: http://dx.doi.org/10.1175/15200434(1999)014<1039:CODOBM>2.0.CO;2

Black, J. E. (2000). Application of weather radar to monitoring numbers of birds in migration. Extended abstract from a presentation given in a Symposium on Weather Radar Ornithology at the joint meeting of the Association of Field Ornithologists/Wilson Ornithological Society/ Gulf Coast Bird Observatory, Galveston, TX, April 2000. Retrieved from http://www.physics.brocku.ca/people/Faculty/Black/Galveston/texas.html

Burger, J. (1983). Jet aircraft noise and bird strikes: why more birds are being hit. Environmental Pollution Series A, Ecological and Biological, 30(2), 143-152. doi: 10.1016/0143-1471(83)90011-9

Burgess, D. W., Magsig, M. A., Wurman, J., Dowell, D. C., \& Richardson, Y. (2002). Radar observations of the 3 May 1999 Oklahoma City tornado. Weather and forecasting, 17(3), 456-471. doi: http://dx.doi.org/10.1175/15200434(2002)017<0456:ROOTMO>2.0.CO;2

Chilson, P. B., Frick, W. F., Kelly, J. F., Howard, K. W., Larkin, R. P., Diehl, R. H., \& Kunz, T. H. (2012). Partly cloudy with a chance of migration: weather, radars, and aeroecology. Bulletin of the American Meteorological Society, 93(5), 669-686. doi: http://dx.doi.org/10.1175/BAMS-D-1100099.1

Crum, T. D., \& Alberty, R. L. (1993). The WSR-88D and the WSR-88D operational support facility. Bulletin of the American Meteorological Society, 74(9), 1669-1687. doi: http://dx.doi.org/10.1175/1520 0477(1993)074<1669:TWATWO>2.0.CO;2

Crum, T. D., Ciardi, E. J., Boettcher, J. B., Istok, M., \& Stern, A. (2013) Benefits for the wind energy industry from the WSR-88D's new dual polarization capability. Fourth Conference on Weather, Climate, and the New Energy Economy, American Meteorological Society. 
Dolbeer, R. A., \& Wright, S. E. (2009). Safety management systems: how useful will the FAA National Wildlife Strike Database be? Human-Wildlife Conflicts, 3, 167-178.

Eastwood, E., Isted, G. A., \& Rider, G. C. (1962). Radar ring angels and the roosting behaviour of starlings. Proceedings of the Royal Society of London B: Biological Sciences, 156(963), 242-267. doi: 10.1098/rspb.1962.0042

Elder, F. C. (1957). Some persistent "Ring Angels" on high-powered radar. In Proceedings Sixth Weather Radar Conference, Cambridge, Massachusetts (pp. 281-290).

Federal Aviation Administration (FAA). (2014). Wildlife strikes to civil aircraft in the United States 1990-2013. Federal Aviation Administration National Wildlife Strike Database Serial Report Number 20, 98. Retrieved from http://wildlife.faa.gov/

Federal Aviation Administration (FAA). (2010). Advisory Circular No. 150/522025 Airport Avian Radar Systems. Federal Aviation Administration, 50. Retrieved from http://www.faa.gov/documentLibrary/media/ Advisory_Circular/150_5220_25.pdf

Gauthreaux Jr, S. A., \& Belser, C. G. (1998). Displays of bird movements on the wsr-88d: patterns and quantification. Weather and Forecasting, 13(2), 453464. doi: http://dx.doi.org/10.1175/15200434(1998)013<0453:DOBMOT>2.0.CO;2

Gauthreaux Jr, S. A., Mizrahi, D. S., \& Belser, C. G. (1998). Bird migration and bias of WSR-88D wind estimates. Weather and Forecasting, 13(2), 465481.

Isom, B. M., Palmer, R. D., Secrest, G. S., Rhoton, R. D., Saxion, D., Allmon, T. L., ... \& Vogt, R. (2009). Detailed observations of wind turbine clutter with scanning weather radars. Journal of Atmospheric and Oceanic Technology, 26(5), 894-910. doi: http://dx.doi.org/10.1175/2008JTECHA1136.1 
Jones, T. A., Christopher, S. A., \& Petersen, W. (2009). Dual-polarization radar characteristics of an apartment fire. Journal of Atmospheric and Oceanic Technology, 26(10), 2257-2269. doi: http://dx.doi.org/10.1175/2009JTECHA1290.1

Kumjian, M. R. (2013). Principles and applications of dual-polarization weather radar. Part I: Description of the polarimetric radar variables. J. Oper. Meteor, 1(19), 226-242. doi: http://dx.doi.org/10.15191/nwajom.2013.0119

Lack, D., \& Varley, G. C. (1945). Detection of birds by radar. Nature, 156, 446.

Maddox, R. A., Howard, K. W., \& Dempsey, C. L. (1997). Intense convective storms with little or no lightning over central Arizona: A case of inadvertent weather modification?. Journal of Applied Meteorology, 36(4), 302-314. doi: http://dx.doi.org/10.1175/15200450(1997)036<0302:ICSWLO>2.0.CO;2

Magsig, M. A., \& Snow, J. T. (1998). Long-distance debris transport by tornadic thunderstorms. Part I: The 7 May 1995 supercell thunderstorm. Monthly weather review, 126(6), 1430-1449. doi: http://dx.doi.org/10.1175/15200493(1998)126<1430:LDDTBT>2.0.CO;2

Martin, W. J., \& Shapiro, A. (2007). Discrimination of bird and insect radar echoes in clear air using high-resolution radars. Journal of Atmospheric and Oceanic Technology, 24(7), 1215-1230. doi: http://dx.doi.org/10.1175/JTECH2038.1

Ryzhkov, A. V., Schuur, T. J., Burgess, D. W., \& Zrnic, D. S. (2005). Polarimetric tornado detection. Journal of applied meteorology, 44(5), 557570. doi: http://dx.doi.org/10.1175/JAM2235.1

Zhang, P., Liu, S., \& Xu, Q. (2005). Identifying Doppler velocity contamination caused by migrating birds. Part I: Feature extraction and quantification. Journal of Atmospheric and Oceanic Technology, 22(8), 1105-1113. doi: http://dx.doi.org/10.1175/JTECH1757.1 